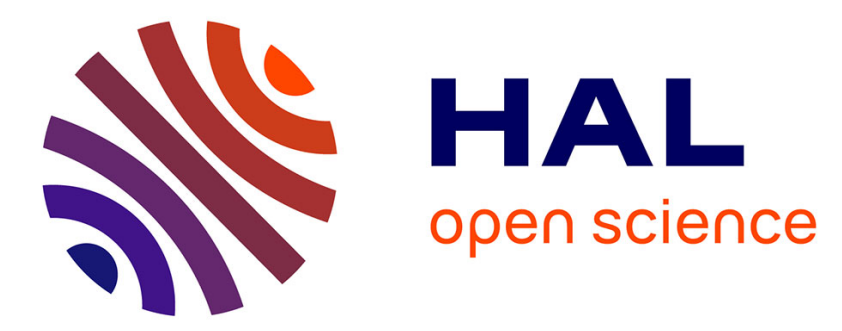

\title{
Selective abolition of Mayer waves in conscious endotoxemic rats
}

Claude Julien, Bruno Chapuis, Christian Barrès

\section{To cite this version:}

Claude Julien, Bruno Chapuis, Christian Barrès. Selective abolition of Mayer waves in conscious endotoxemic rats. Autonomic Neuroscience: Basic and Clinical, 2020, 226, pp.102673. 10.1016/j.autneu.2020.102673 . hal-03031515

\section{HAL Id: hal-03031515 https://hal.science/hal-03031515}

Submitted on 4 Dec 2020

HAL is a multi-disciplinary open access archive for the deposit and dissemination of scientific research documents, whether they are published or not. The documents may come from teaching and research institutions in France or abroad, or from public or private research centers.
L'archive ouverte pluridisciplinaire HAL, est destinée au dépôt et à la diffusion de documents scientifiques de niveau recherche, publiés ou non, émanant des établissements d'enseignement et de recherche français ou étrangers, des laboratoires publics ou privés. 


\section{Selective abolition of Mayer waves in conscious endotoxemic rats}

Claude Juliena, ${ }^{\mathrm{a}}$, Bruno Chapuis ${ }^{\mathrm{b}}$, Christian Barrès ${ }^{\mathrm{a}}$

a EA 7426: Pathophysiology of Injury-Induced Immunosuppression $\left(\mathrm{PI}^{3}\right)$, Université Claude Bernard - Lyon 1, Lyon, France

Postal address: 8 avenue Rockefeller, 69008 Lyon, France

E-mail addresses: claude.julien@univ-lyon1.fr; christian.barres@univ-lyon1.fr

b Centre d'Imagerie Quantitative Lyon-Est, Lyon Multiscale Imaging Center, Université Claude Bernard - Lyon 1, Lyon, France

Postal address: 8 avenue Rockefeller, 69008 Lyon, France

Email address: bruno.chapuis@univ-lyon1.fr

${ }^{*}$ Corresponding author.

\section{Abstract}

The relation between vascular sympathetic tone and the amplitude of arterial pressure (AP) Mayer waves was examined by analyzing 60-min recordings of AP and renal sympathetic nerve activity (RSNA) obtained in conscious rats before and after lipopolysaccharide administration, which results in strong sympathoexcitation. Mayer waves completely disappeared together with accompanying oscillations of RSNA. Meanwhile, the gain of the sympathetic baroreceptor reflex was increased, thus suggesting that abolition of Mayer waves resulted from the previously reported reduction of vascular reactivity to $\alpha$-adrenoceptor stimulation. In conclusion, the amplitude of Mayer waves cannot be used indiscriminately as an index of vascular sympathetic tone.

Word count: 100 words

Keywords: arterial pressure; baroreflex; Mayer waves; renal sympathetic nerve activity. 


\section{Introduction}

Mayer waves are sympathetically mediated oscillations of arterial pressure (AP) slower than respiration (Julien 2006, 2020), and are often qualified as low-frequency (LF) oscillations. Their characteristic frequency is $\sim 0.1 \mathrm{~Hz}$ in humans and $\sim 0.4 \mathrm{~Hz}$ in rats. These oscillations are closely associated with LF oscillations of sympathetic nervous activity (SNA) to the skeletal muscle circulation in humans and to the renal circulation in rats (Julien, 2006). Mayer waves occur spontaneously in conscious resting subjects but are usually amplified during states of sympathetic activation, such as those induced by orthostatic stress, moderate intensity physical exercise or mental stress (Julien 2006; Kanbar et al., 2007a). However, decreased LF oscillations of muscle SNA associated with sympathetic overactivity have been described in patients with severe heart failure (van de Borne et al., 1997).

The relation between the amplitude of Mayer waves and the level of SNA is possibly nonlinear, and might be better described by a bell-shaped curve, with increases at moderate levels of sympathetic activation and a reversal at higher levels (Bertram et al., 2005). In the latter study, however, changes in SNA were baroreflexly mediated via the infusion of vasoactive drugs. To further examine this question, we analyzed the effect on Mayer waves and accompanying LF oscillations of RSNA of sympathoexcitation induced by infusion of lipopolysaccharide (LPS) in conscious rats (Julien et al., 2017). 


\section{Materials and methods}

\subsection{General procedures}

The surgical procedures and experimental protocol have been extensively described in a previous report (Julien et al., 2017). Briefly, 10 adult male SpragueDawley rats were chronically instrumented with femoral arterial and venous catheters and a bipolar electrode around the left renal sympathetic nerve. The following day, the AP and rectified renal SNA (RSNA) signals were sampled at 500 and $5000 \mathrm{~Hz}$, respectively. All experiments were performed under cardiac autonomic blockade (atenolol and methylatropine, $2 \mathrm{mg} / \mathrm{kg}$ each followed by $2 \mathrm{mg} / \mathrm{kg} / \mathrm{h} \mathrm{IV}$ ) for assessment of vascular reactivity to $\alpha$-adrenoceptor stimulation with phenylephrine (Julien et al., 2017). Two periods were selected for analysis, one 60 -min period under baseline conditions, and one 60-min period initiated after induction of endotoxemia with LPS infusion (20 mg/kg IV over $15 \mathrm{~min}$ ).

\subsection{Data analysis}

All AP and RSNA data were resampled at $50 \mathrm{~Hz}$ and segmented into 2048-point periods (40.96 s) overlapping by half. After applying a Hanning window, a fast Fourier transform analysis was performed and average spectra were computed for each rat (Bertram et al., 2005). Spectral power was calculated in selected frequency bands as follows: very-low frequency (VLF, 0-0.3 Hz), low-frequency (LF, 0.3-0.6 Hz), highfrequency $(\mathrm{HF}, 0.6-2.5 \mathrm{~Hz}$ ), cardiac-related $(\mathrm{CR})$ band centered on mean heart rate $( \pm 0.5 \mathrm{~Hz}$ ), and very-high frequency (VHF, from the upper limit of the CR band up to $25 \mathrm{~Hz}$ ). Total power was computed from 0 to $25 \mathrm{~Hz}$.

The sensitivity of the sympathetic nervous component of the baroreceptor reflex was computed as the gain of the transfer function relating RSNA to AP in the heart rate range (Kanbar, 2007b). The gain was calculated at the frequency where maximum, significant coherence was observed (Gallet and Julien, 2011).

Values are expressed as means \pm SEM. In each band, the Wilcoxon signed-rank test for paired comparisons was used to assess the significance of differences between control and endotoxemic conditions. 


\section{Results}

\subsection{Effect of LPS administration on total and VLF powers of AP and RSNA}

The effects of LPS-induced endotoxemia on mean levels of AP, RSNA and heart rate have been reported in Julien et al. (2017). In brief, LPS administration decreased the mean AP level $(-7 \pm 2 \%, p<0.01)$ and strongly increased the mean RSNA level (304 $\pm 59 \%, p<0.01)$. Despite autonomic blockade, there was a slight decrease in heart rate $(-8 \pm 3 \%, p<0.05)$.

Total and VLF powers of AP decreased markedly, whereas total power of RSNA was more than doubled and its VLF power did not change significantly (Table 1).

\subsection{Effect of LPS administration on Mayer waves and related RSNA oscillations}

In the LF band, LPS administration decreased AP spectral power by $>90 \%$ and RSNA power by $>60 \%$ (Table 1 ). In addition, and for both AP and RSNA, there was not any discernible peak in the band, contrary to baseline conditions (Fig. 1).

\subsection{Effect of LPS administration on respiratory related variability}

After LPS administration, it was observed that AP and RSNA spectral power linked to respiration tended to be shifted towards lower values and was much less spread over the band (Fig. 1), pointing to slightly slower and more regular respiratory movements. Spectral power increased in 8 of 10 rats for AP and in 6 of 10 rats for RSNA.

\subsection{Effect of LPS administration on CR and VHF powers of AP and RSNA}

The CR power of AP markedly decreased, and this was accompanied by a large decrease in its VHF power. On the contrary, the CR power of RSNA strongly increased as well as its VHF power (Table 1). 
3.5. Effect of LPS administration on the spontaneous sympathetic baroreflex gain

The spontaneous sympathetic baroreflex gain could be computed in all rats and under both conditions, as coherence between AP and RSNA was always significant, both before $(0.70 \pm 0.05$ at $6.2 \pm 0.1 \mathrm{~Hz}, \mathrm{n}=10)$ and after $(0.84 \pm 0.04$ at $5.5 \pm 0.2 \mathrm{~Hz}$, $\mathrm{n}=10$ ) LPS administration. The gain of the transfer function increased significantly ( $p=0.005$ ) from $0.016 \pm 0.005$ to $0.039 \pm 0.012 \mu \mathrm{V} / \mathrm{mmHg}$ after LPS infusion. 


\section{Discussion}

This novel analysis of previously collected data (Julien et al., 2017) shows that in conscious endotoxemic rats, strong sympathoexcitation is accompanied by a profound and complex pattern of changes in AP variability, and even more so, in RSNA variability. The most impressive and consistent change is the complete disappearance of Mayer waves and of accompanying RSNA oscillations. Endotoxemia, therefore, is a previously unrecognized situation of sympathetic overactivity resulting in the abolition of Mayer waves.

LPS administration had profound and almost immediate behavioral effects, namely, decreases in the performance of activities that were frequently or occasionally displayed under control conditions, such as exploring, grooming, eating or drinking. It has been shown that these natural behaviors invariably induce changes in AP and RSNA (Miki et al., 2005), which are erratic and rather long lasting, and thus, contribute to VLF power in the spectra. The apparent sedation of rats after LPS infusion was therefore mainly responsible for the decrease in AP VLF power. RSNA VLF power did not change significantly, probably because the expected decrease was partly offset by the large increase in the mean RSNA level that tended to affect all components of its variability (Bertram et al., 2005).

As mentioned in the Results section, respiratory related variability tended to be increased after LPS, possibly as a consequence of the slowing down of respiratory movements and the ensuing increase in tidal volume.

The CR powers of AP and RSNA varied in opposite directions. The decrease in AP CR power points to a decrease in the pulse pressure, which was indeed observed in recordings of AP, as showed by Fig. 2 in Julien et al. (2017). This acute decrease is likely to reflect a fall in cardiac output mainly resulting from a reduction in left ventricular stroke volume (Mulder et al., 1996). Not surprisingly, VHF power of AP, which is almost entirely constituted by harmonics of the $C R$ peak, was also decreased. By contrast, CR power of RSNA was amplified, which is consistent with an increased sensitivity of the sympathetic nervous component of the baroreceptor reflex (Tohyama et al., 2018). This was indeed confirmed by the calculation of the transfer function relating RSNA to AP (Kanbar et al., 2007b). VHF power of RSNA strongly increased, which reflects the contribution of VHF components to the mean level of RSNA (Bertram et al., 2005; Chapuis et al., 2010). 
The effects of experimental endotoxemia or clinical sepsis on AP and SNA variability have scarcely been examined. In critically ill patients, it was reported that LF power of AP was shifted towards lower frequencies $(\sim 0.02 \mathrm{~Hz}$; Berg et al., 2016). No indication was given, however, of the sympathetic origin of this power in this study. In experimental animals, we have been unable to locate any report about the effects of LPS-induced endotoxemia on AP and SNA variability. One article reported on the chronic effects on AP and RSNA of IV infusion of Escherichia coli in conscious sheep, but no mention was made about its variability (Lankadeva et al., 2015). The suppression of Mayer waves in endotoxemic rats is an original and intriguing finding. Mayer waves originate from instability in the sympathetic baroreflex loop, and their amplitude depends on at least two factors: (1) the strength of the slow perturbations affecting AP, and (2) the sensitivity of the sympathetic vascular component of the baroreceptor reflex (Julien, 2006). Slow AP perturbations produce spectral power in the VLF band. In the present study, decreased VLF power of AP may have contributed to suppression of Mayer waves. However, this effect should have been, at least partly, compensated for by the enhanced sensitivity of the sympathetic limb of the baroreceptor reflex. In a previous study on conscious rats, it was shown that progressively decreasing AP with sodium nitroprusside caused sympathoexcitation associated with a proportional increase in the amplitude of RSNA oscillations in the Mayer band. Below a certain limit (about $-20 \mathrm{mmHg}$ ), however, there was an almost complete reversal of the latter effect. A very similar pattern of changes in CR oscillations was observed. A model of dynamic baroreceptor function, incorporating a pressure threshold above which baroreceptors start to discharge, accounted for the bell-shaped curve of the latter relation (Bertram et al., 2005). The model is valid in this frequency range because the reflex operates open loop (Julien, 2006). However, to apply the model to oscillations of RSNA in the LF band, where the reflex operates closed loop, it is necessary to assume that the properties of the vascular limb of the sympathetic baroreceptor reflex (from SNA to AP) are preserved. This was probably the case in the study by Bertram et al. (2005), but not in the present one. We have indeed shown in the present series of rats that vascular reactivity to $\alpha$-adrenoceptor stimulation was strongly diminished ( $\mathrm{ED}_{50}$ to phenylephrine was increased 4 to 5 times after LPS administration; Julien et al., 2017). This conclusion accords with the effects of acute $\alpha$-adrenoceptor blockade with phentolamine in conscious rats (Barrès 
et al., 2001). In this study, we observed that phentolamine decreased AP, increased RSNA and eliminated Mayer waves and accompanying RSNA oscillations.

Increased sensitivity of the sympathetic nervous component of the baroreflex during LPS-induced endotoxemia is not an original finding. In a previous study on anesthetized rats (Tohyama et al., 2018), animals were challenged with LPS (60 $\mu \mathrm{g} / \mathrm{kg}$ IV). It was reported that sympathoexcitation developed slowly and that this was accompanied by a progressive increase in the sensitivity of the sympathetic nervous component of the baroreflex, together with a progressive decrease in AP responsiveness to SNA. To our knowledge, the cardiac vagal component of the reflex has been studied on two occasions in LPS infused rats, and was reported to be impaired (Liu et al., 2011; Radaelli et al., 2013). Because the rats of the present study were under complete cardiac autonomic blockade, it was impossible to examine this question.

\section{Conclusion}

It is still widely accepted that changes in the amplitude of Mayer waves can be related to changes in SNA, including in septic shock patients (Carrara et al., 2018). We provide here the demonstration that in conscious endotoxemic rats, changes in Mayer waves are completely dissociated from changes in RSNA. This observation prompts to use with great caution the amplitude of Mayer waves as an index of the SNA level.

\section{Declaration of competing interest}

None of the authors have any conflicts of interest to declare. 


\section{References}

Barrès, C., de Souza Neto, E.P., Julien, C., 2001. Effect of alpha-adrenoceptor blockade on the $0.4-\mathrm{Hz}$ sympathetic rhythm in conscious rats. Clin. Exp. Pharmacol. Physiol. 28, 983-985.

Berg, R.M., Plovsing, R.R., Greve, A.M., Christiansen, C.B., Toksvang, L.N., Holstein-Rathlou, N.H., Møller, K., 2016. Spontaneous blood pressure oscillations in mechanically ventilated patients with sepsis. Blood Press. Monit. $21,75-79$.

Bertram, D., Oréa, V., Chapuis, B., Barrès, C., Julien, C., 2005. Differential responses of frequency components of renal sympathetic nerve activity to arterial pressure changes in conscious rats. Am. J. Physiol. Regul. Integr. Comp. Physiol. 289, R1074-R1082.

Carrara, M., Bollen Pinto, B., Baselli, G., Bendjelid, K., Ferrario, M., 2018. Baroreflex sensitivity and blood pressure variability can help in understanding the different response to therapy during acute phase of septic shock. Shock. 50, 78-86.

Chapuis, B., Oréa, V., Barrès, C., Julien, C., 2010. Very high frequency components of renal sympathetic nerve activity in conscious rats. Auton. Neurosci. 152, 5559.

Gallet, C., Julien, C., 2011. The significance threshold for coherence when using the Welch's periodogram method: Effect of overlapping segments. Biomed. Signal Process. Control. 6, 405- 409.

Julien, C., 2006. The enigma of Mayer waves: Facts and models. Cardiovasc. Res. $70,12-21$. 
Julien, C., 2020. An update on the enigma of Mayer waves. Cardiovasc. Res. doi:10.1093/cvr/cvz327.

Julien, C., Oréa, V., Quintin, L., Piriou, V., Barrès, C., 2017. Renal sympathetic nerve activity and vascular reactivity to phenylephrine after lipopolysaccharide administration in conscious rats. Physiol. Rep. 5, e13139.

Kanbar, R., Oréa, V., Barrès, C., Julien, C., 2007a. Baroreflex control of renal sympathetic nerve activity during air-jet stress in rats. Am. J. Physiol. Regul. Integr. Comp. Physiol. 292, R362-R367.

Kanbar, R., Oréa, V., Chapuis, B., Barrès, C., Julien, C., 2007b. A transfer function method for the continuous assessment of baroreflex control of renal sympathetic nerve activity in rats. Am. J. Physiol. Regul. Integr. Comp. Physiol. 293, R1938R1946.

Lankadeva, Y.R., Booth, L.C., Kosaka, J., Evans, R.G., Quintin, L., Bellomo, R., May, C.N., 2015. Clonidine restores pressor responsiveness to phenylephrine and angiotensin II in ovine sepsis. Crit. Care Med. 43, e221-e229.

Liu C, Zhang, G.F., Song, S.W., Cai, G.J., Liu, W.H., Miao, C.Y., Su, D.F., 2011. Effects of ketanserin on endotoxic shock and baroreflex function in rodents. J. Infect. Dis. 204, 1605-1612.

Mulder, M.F., van Lambalgen, A.A., van den Bos, G.C., Thijs, L.G., 1996. The fall of cardiac output in endotoxemic rats cannot explain all changes in organ blood flow: a comparison between endotoxin and low venous return shock. Shock. 5 , 135-140.

Radaelli, A., Castiglioni, P., Cerrito, M.G., De Carlini, C., Soriano, F., Di Rienzo, M., Lavitrano, M.L., Paolini, G., Mancia, G., 2013. Infusion of Escherichia coli 
lipopolysaccharide toxin in rats produces an early and severe impairment of baroreflex function in absence of blood pressure changes. Shock. 39, 204-209.

Tohyama, T., Saku, K., Kawada, T., Kishi, T., Yoshida, K., Nishikawa, T., Mannoji, H., Kamada, K., Sunagawa, K., Tsutsui, H., 2018. Impact of lipopolysaccharideinduced acute inflammation on baroreflex-controlled sympathetic arterial pressure regulation. PLoS One. 13(1), e0190830.

van de Borne, P., Montano, N., Pagani, M., Oren, R., Somers, V.K., 1997. Absence of low-frequency variability of sympathetic nerve activity in severe heart failure. Circulation. 95, 1449-1454. 


\section{Table 1}

Effect of lipopolysaccharide (LPS) administration on variability of arterial pressure $(A P)$ and renal sympathetic nerve activity (RSNA) in 10 conscious rats.

\begin{tabular}{lccc}
\hline $\mathrm{AP}\left(\mathrm{mmHg}^{2}\right)$ & Baseline & LPS & $\mathrm{p}$ \\
\hline Ptot $(0-25 \mathrm{~Hz})$ & $243 \pm 11$ & $122 \pm 9$ & 0.005 \\
VLF $(0-0.3 \mathrm{~Hz})$ & $10 \pm 2$ & $2.3 \pm 0.3$ & 0.005 \\
LF $(0.3-0.6 \mathrm{~Hz})$ & $6.5 \pm 3.7$ & $0.55 \pm 0.10$ & 0.005 \\
HF $(0.6-2.5 \mathrm{~Hz})$ & $2.2 \pm 1.4$ & $2.5 \pm 0.2$ & 0.075 \\
$\mathrm{CR}(\mathrm{HR} \pm 0.5 \mathrm{~Hz})$ & $172 \pm 8$ & $77 \pm 7$ & 0.005 \\
VHF $(\mathrm{HR}+0.5-25 \mathrm{~Hz})$ & $53 \pm 3$ & $39 \pm 2$ & 0.017
\end{tabular}

RSNA (\% change from baseline)

\begin{tabular}{lccc}
\hline Ptot $(0-25 \mathrm{~Hz})$ & - & $118 \pm 32$ & 0.028 \\
$\operatorname{VLF}(0-0.3 \mathrm{~Hz})$ & - & $45 \pm 61$ & 0.285 \\
$\mathrm{LF}(0.3-0.6 \mathrm{~Hz})$ & - & $-62 \pm 11$ & 0.008 \\
$\mathrm{HF}(0.6-2.5 \mathrm{~Hz})$ & - & $50 \pm 29$ & 0.139 \\
$\mathrm{CR}(\mathrm{HR} \pm 0.5 \mathrm{~Hz})$ & - & $339 \pm 115$ & 0.009 \\
VHF $(\mathrm{HR}+0.5-25 \mathrm{~Hz})$ & - & $193 \pm 36$ & 0.005
\end{tabular}

Variability was estimated as the spectral power in selected frequency bands. Ptot, total power; VLF, very-low frequency power; LF, low-frequency power; HF, highfrequency power; CR, cardiac-related power; HR, heart rate; VHF, very-high frequency. $p$ values contained in the column refer to paired comparisons (Wilcoxon signed rank test) between basal and endotoxemic conditions. 


\section{Legend to Fig. 1:}

Example of AP (A) and RSNA (B) power spectra computed in a conscious rat before (black traces) and after (grey traces) LPS administration. The frequency scale was chosen to emphasize the LF and HF bands containing Mayer waves and respiratory related oscillations, respectively. The vertical dotted lines delimit the LF band. Note especially the disappearance of the peaks produced by Mayer waves and accompanying RSNA oscillations under endotoxemic condition. In this particular rat, LPS infusion increased the mean level of RSNA from 2.0 to $6.1 \mu \mathrm{V}$. 

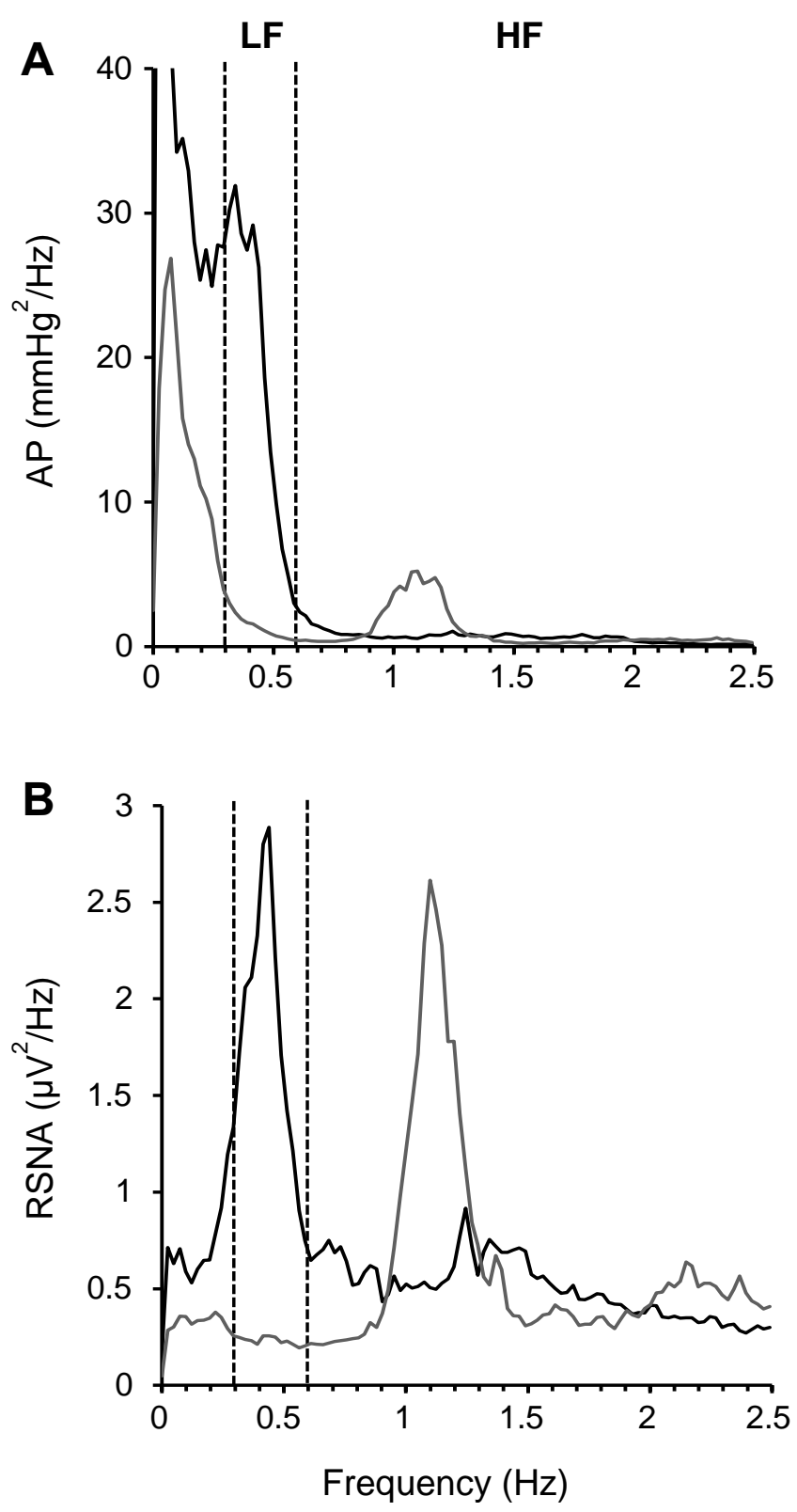

Fig. 1 